Article

\title{
Solid State Electronic Sensors for Detection of Carbon Dioxide
}

\author{
Ami Hannon ${ }^{1}$ and Jing $\mathrm{Li}^{2, *}$ \\ 1 KBR Wyle Inc. at NASA Ames Research Center, CA 94035, USA \\ 2 NASA Ames Research Center, CA 94035, USA \\ * Correspondence: jing.li-1@nasa.gov; Tel.: +1-650-604-4352
}

Received: 10 July 2019; Accepted: 1 September 2019; Published: 6 September 2019

\begin{abstract}
Detection of carbon dioxide $\left(\mathrm{CO}_{2}\right)$ is very important for environmental, health, safety and space applications. We have studied novel multiwall carbon nanotubes (MWCNTs) and an iron oxide $\left(\mathrm{Fe}_{2} \mathrm{O}_{3}\right)$ nanocomposite based chemiresistive sensor for detection of $\mathrm{CO}_{2}$ at room temperature. The sensor has been miniaturized to a chip size $(1 \mathrm{~cm} \times 2 \mathrm{~cm})$. Good sensing performance was observed with a wide detection range of $\mathrm{CO}_{2}$ concentrations (100-6000 ppm). Structural properties of the sensing materials were characterized using Field-Emission Scanning Electron Microscopy, Fourier-Transform Infrared and Raman spectroscopies. The greatly improved sensitivity of the composite materials to $\mathrm{CO}_{2}$ can be attributed to the formation of a depletion layer at the p-n junction in an MWCNT/iron oxide heterostructure, and new $\mathrm{CO}_{2}$ gas molecules adhere to the high surface area of MWCNTs due to the concentration gradient. The test results showed that the $\mathrm{CO}_{2}$ sensor possesses fast response, compact size, ultra-low power consumption, high sensitivity and wide dynamic detection range.
\end{abstract}

Keywords: carbon dioxide sensor; $\mathrm{CO}_{2}$ sensor; gas sensor; room temperature gas sensing; functionalized nanotubes; electronic nose; smartphone sensor; chemiresistive sensor; nanocomposite

\section{Introduction}

There is a great demand for an effective solid-state electronic device to monitor carbon dioxide $\left(\mathrm{CO}_{2}\right)$ in a variety of applications such as global warming, air quality control, healthcare, mining and the food industry. $\mathrm{CO}_{2}$ detection is crucial at the international space station in the crew cabin for the astronaut's health and safety. The $\mathrm{CO}_{2}$ sensor can be used to monitor the $\mathrm{CO}_{2}$ concentration in the air of the crew cabin during $\mathrm{CO}_{2}$ sequestration processes to make sure that $\mathrm{CO}_{2}$ is scrubbed. $\mathrm{CO}_{2}$ is a harmful pollutant at higher concentrations due to its ability to displace oxygen in large concentrations. There is about $0.04 \%$ (400 ppm) $\mathrm{CO}_{2}$ present in ambient air and it is harmless, but once concentration surpasses $1 \%$, it begins to have harmful effects on the human body [1,2]. Headaches start within a few hours of $\mathrm{CO}_{2}$ levels of $2-3 \%$. At $4-5 \% \mathrm{CO}_{2}$, dizziness, increased blood pressure and breathing issues take hold. Levels above $5 \%$ begin to incapacitate the worker. Coma and possible death can occur within minutes at $17 \% \mathrm{CO}_{2}$. The Occupational Safety and Health Administration's permissible exposure limit for $\mathrm{CO}_{2}$ is $0.5 \%$ (5000 ppm) averaged over an $8 \mathrm{~h}$ work day [3]. $\mathrm{CO}_{2}$ toxicity can be extremely dangerous for workers in confined environments, such as the crew cabin in space, an underground mine and the crew cabin in a submarine. The dangers of this gas when inhaled prompt the need for a sensor that can identify and alert immediately and accurately as soon as $\mathrm{CO}_{2}$ concentration reaches toxic levels.

The state-of-the-art commercial sensors for $\mathrm{CO}_{2}$ are nondispersive infrared (NDIR) sensors [4]. However, they have issues with precision at different temperatures, pressures and high humidity levels. The NDIR sensor works by comparing how much IR light is absorbed by $\mathrm{CO}_{2}$ with how 
much was emitted to correlate its ratio to $\mathrm{CO}_{2}$ concentration. The accuracy becomes problematic when the gas absorption lines begin to broaden due to local effects of humidity. At higher pressures, temperatures and humidity levels, radiating and collision time increase, causing the absorption lines to be broaden [5]. Although the NDIR sensor has been miniaturized lately, it is still much larger compared with the electronic sensor that can be made in chip size. In nanotechnology research, sensors for $\mathrm{CO}_{2}$ are currently being developed such as silicon nanowires, $\mathrm{Sn}_{2} \mathrm{O}_{3}$ microspheres and polymer nanofilms [6-8]. Metal oxides have been used extensively in commercial sensors for many years. They provide high sensitivity to different gases and offer quick response time. Their issue is that they need high operating temperatures, which can be dangerous in flammable environments and also draw large amounts of power [9]. Polymer sensors suffered low sensitivity due to their swelling mechanism for gas sensing. This gives evidence for the need for a more reliable and versatile sensor with a quick response time, wide detection range, in situ monitoring, low power consumption, operation at room temperature and small size.

Carbon nanotubes (CNTs) are an extremely useful sensing material due to their mechanical and thermal stability, electrical conductivity and the ability to adsorb gases [10]. It is a one-dimensional material, which allows almost its entire surface to be available for gas adsorption and charge transfer process [11]. Therefore, it becomes possible to achieve high sensitivity, down to $<1 \mathrm{ppb}$, and it can react to a single foreign gas molecule $[12,13]$. The electrical characteristics of CNTs are heavily influenced by gases that donate or accept electrons [11]. $\mathrm{CO}_{2}$ is a weak oxidizing gas and once it interacts with the CNTs, it will take electrons from the material [14], which is reflected in a measurable resistance change of the carbon nanotubes. Carbon nanotubes have a very high surface area to volume ratio [13], which can be used to improve the sensitivity by using less mass. Pristine CNTs do not contain functional groups, which are needed for specific gas adsorption. It is possible to functionalize and/or dope the CNTs, or to create CNT composite materials that can adsorb a particular type of gas molecules to improve the selectivity [13].

We have developed a composite material using multiwall-carbon nanotubes (MWCNTs) and iron oxide for $\mathrm{CO}_{2}$ detection. The carbon nanotubes can adsorb more $\mathrm{CO}_{2}$ molecules due to their large surface area, and the iron oxide nanoparticles act as the binding sites to interact with $\mathrm{CO}_{2}$ and cause the resistance change due to the charge transfer between the MWCNT/iron oxide and $\mathrm{CO}_{2}$. Our MWCNT/iron oxide composite allows operation at room temperature and maintains a sensitive and fast response to $\mathrm{CO}_{2}[12,13]$ with a small footprint. Our sensor has its uniqueness, such as small size of $1 \mathrm{~cm} \times 2 \mathrm{~cm}$, low power consumption of micro watts and 2-terminal current-voltage measurement that can be easily multiplexed and integrated with existing electronics. This device can be used with wired and wireless network sensing.

This paper describes a chemiresistive sensor utilizing the selective properties of a MWCNT/iron oxide composite to detect $\mathrm{CO}_{2}$ gas from $100 \mathrm{ppm}$ to $0.5 \% \mathrm{CO}_{2}$ (OSHA exposure limit).

\section{Materials and Methods}

Sensing Materials Synthesis. Multi-wall carbon nanotubes (MWCNTs) were purchased from Nanostructured \& Amorphous Materials, Inc. (Houston, TX, USA) and iron oxide was purchased from US Research Nanomaterials, Inc (Houston, TX, USA). All other chemicals such as nitric acid $\left(\mathrm{HNO}_{3}\right)$ and sulfuric acid were obtained from Sigma Aldrich. MWCNTs were first oxidized using mixed acid. MWCNTs were refluxed in mixed acid consisting of concentrated sulfuric acid $\left(98 \% \mathrm{H}_{2} \mathrm{SO}_{4}\right)$ and nitric acid $\left(68 \% \mathrm{HNO}_{3}\right)$ with the volume ratio of $3: 1$, at $120{ }^{\circ} \mathrm{C}$ for $2 \mathrm{~h}$. Dilution, decantation and centrifugation were repeated, followed by rinsing it in water. The purified MWCNTs were then dried at $125^{\circ} \mathrm{C}$ for $3 \mathrm{~h}$ using a programmable oven. Well dispersed solutions of the oxidized MWCNTs were made in water. Composite materials were prepared by varying weight percentages of the iron oxide $\left(\mathrm{Fe}_{2} \mathrm{O}_{3}\right)$ in the MWCNTs. Four different composite materials were prepared based on iron oxide weight percent- $5 \%, 4 \%, 3 \%$ and $2 \%$. 
Sensor Chip Preparation. The substrate of the sensor chip $(1 \mathrm{~cm} \times 2 \mathrm{~cm})$ is made by a grade FR-4 printed circuit board (PCB). This sensor chip consisted of 16 pairs of gold interdigitated electrodes (IDE) screen printed on the PCB substrate. Each pair of IDE is called a sensor or a channel that has the following dimensions: finger width of $70 \mu \mathrm{m}$, finger gap sizes of $100 \mu \mathrm{m}$.

The sensing material of the oxidized MWCNT/iron oxide composite was deposited onto the chips by drop casting using a micropipette. Each IDE array had $0.3 \mu \mathrm{L}$ of the composite materials in aqueous solution. A total of 8 channels were deposited with two different sensing materials. Four sensors (channels 1-4) were coated with the oxidized MWCNT/iron oxide nanocomposite and the next four (channels 5-8) were coated with oxidized MWCNTs without iron oxide for comparison. For the sensing material selection, all 16 channels of another chip were used by depositing 4 different composites of MWCNT/iron oxide at different ratios.

Sensor Testing. $\mathrm{CO}_{2}$ gas exposure tests were conducted by attaching a sensor chip to an adapt board and then to a Keithley 2700 (Keithley Instruments, Inc., Scottsdale, AZ, USA) to measure the electrical resistance value of each channel on the sensor chip. An Environics 2000 (Environics Inc., Tolland, CT, USA) gas blending and dilution system is used for introducing $\mathrm{CO}_{2}$ gas at different concentrations in air. The certified gases supplied were 10,000 ppm $\mathrm{CO}_{2}$ (Matheson) and Zero Air (Praxair). A Teflon cover with a nozzle combined with the sensor chip adapt board was used to form a test chamber for introducing the $\mathrm{CO}_{2}$ gas stream directly onto the surface of the sensor chip. The gas stream of $400 \mathrm{~cm}^{3} / \mathrm{min}$ was used for $\mathrm{CO}_{2}$ gas exposure and sensor testing. The sensor testing setup is depicted in Figure 1. During the experiment, an initial trial of dry air flew onto the sensor chip for $10 \mathrm{~min}$ to establish a baseline for the following $\mathrm{CO}_{2}$ exposure and dry air flush cycles. The gas stream of $\mathrm{CO}_{2}$ in air was introduced to the sensor chip for $1 \mathrm{~min}$ followed by a $5 \mathrm{~min}$ dry air flush. The $\mathrm{CO}_{2}$ concentrations were increased from $100 \mathrm{ppm}$ to $6000 \mathrm{ppm}$, and each concentration of the $\mathrm{CO}_{2}$ exposure was for $1 \mathrm{~min}$ followed by a $5 \mathrm{~min}$ dry air flush. A repeatability test was conducted following the same schedule except instead of increasing concentration of $\mathrm{CO}_{2}$; it stayed at $4000 \mathrm{ppm}$ consistently. A test of step response with increasing $\mathrm{CO}_{2}$ concentration and an air purging at the end of the test was also conducted.

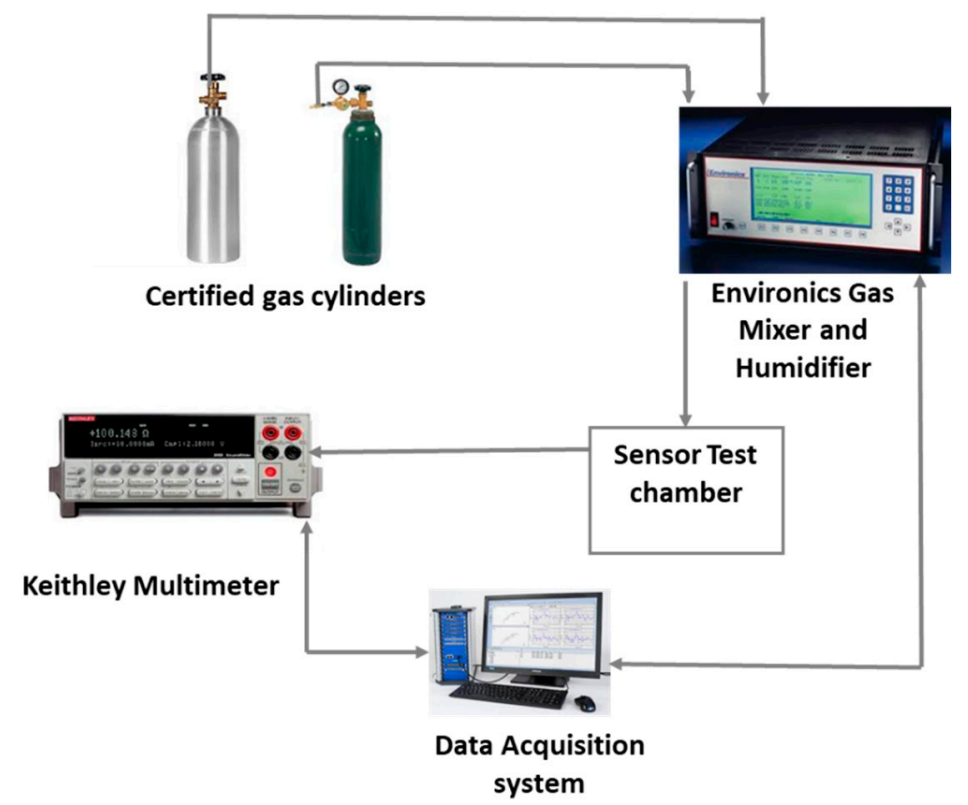

Figure 1. Gas sensor test set-up. 


\section{Results and Discussion}

\subsection{Optimization of Sensing Material}

First of all, to optimize the ratio of the composite sensing material, four different composite sensing materials with oxidized MWCNTs were prepared by varying the iron oxide weight percentage. A sensor chip containing 16 IDEs was used for the deposition of these four different materials. Each material was deposited on four channels by drop casting. After room temperature drying and vacuum oven drying to remove any remaining water, the resistances of all the channels were measured. Channels $1-4$, which were deposited with $5 \%$ (by weight) iron oxide, did not show any conductance (an open circuit) due to the amount of non-conductive iron oxide nanoparticles in the composite. Channels 5-8 were deposited with $4 \%$ iron oxide and displayed an average resistance of $\sim 123 \mathrm{~K} \Omega$. Channels 9-12 deposited with $3 \%$ iron oxide showed an average resistance of $\sim 3.8 \mathrm{~K} \Omega$. Channels $13-16$ deposited with $2 \%$ iron oxide showed an average resistance of $\sim 0.7 \mathrm{~K} \Omega$. This chip was then exposed to various concentration of $\mathrm{CO}_{2}$ in the ranges of 100-6000 ppm at room temperature, as shown in the Figure 2. All three composite materials $\left(4 \%, 3 \%\right.$ and $2 \%$ ) responded well to $\mathrm{CO}_{2}$, but the sensitivity to $\mathrm{CO}_{2}$ decreased as the iron oxide percent decreased. Sensor channels with $4 \%$ iron oxide showed highest relative change to $\mathrm{CO}_{2}$ exposure compared to the other three materials, but the higher base resistance made it noisier compared to other compositions. Based on this data, we decided to go with $3.5 \%$ iron oxide for further tests as that showed a reasonably high sensitivity and a stable base resistance.

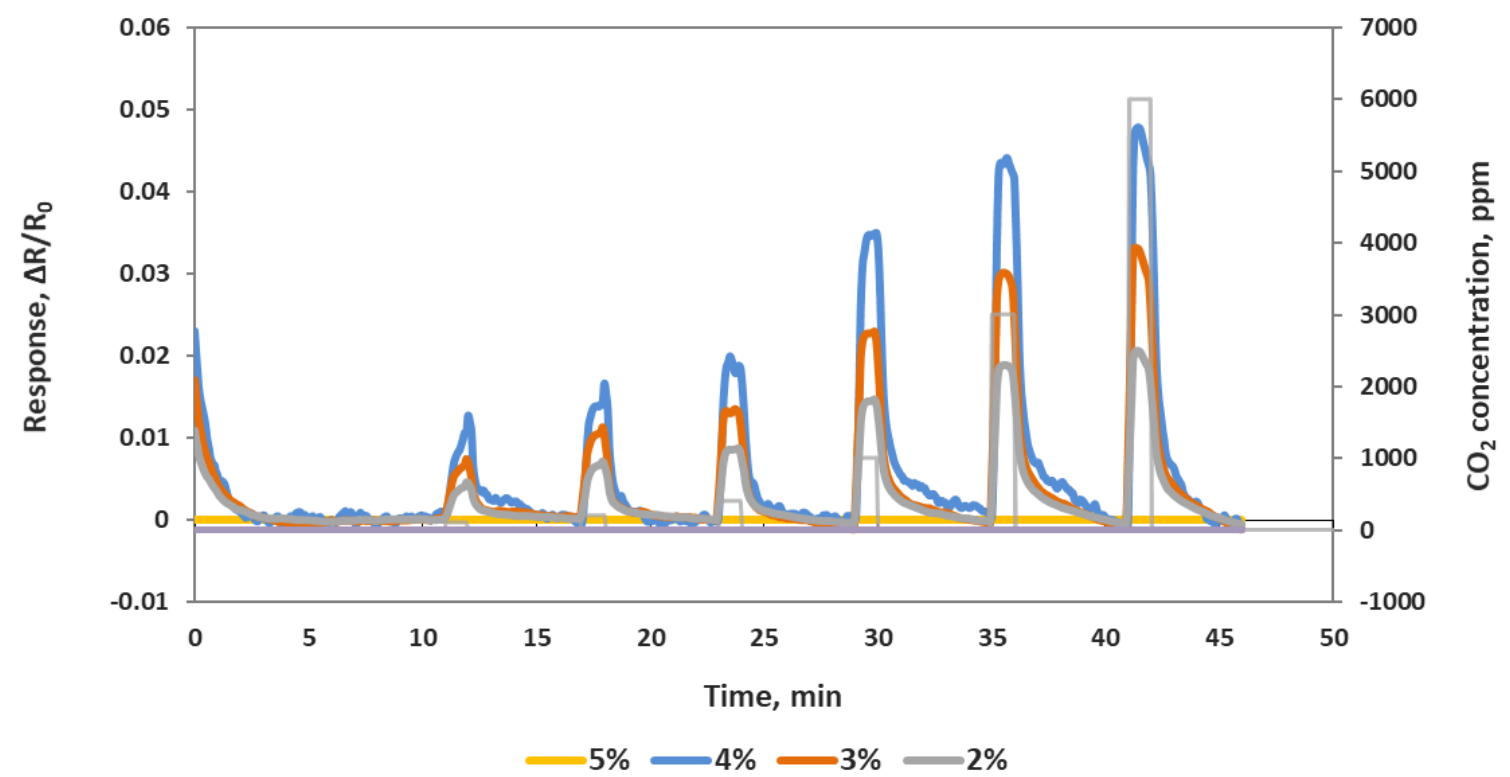

Figure 2. Response of a sensor chip to 100, 200, 400, 1000, 3000 and 6000 ppm $\mathrm{CO}_{2}$. Each line is an average of full identical channels.

For the rest of the $\mathrm{CO}_{2}$ study, we used the 3.5\% oxidized MWCNT/iron oxide composite material. We prepared a sensor chip with four channels of the composite material and four channels of oxidized MWCNTs without iron oxide.

\subsection{Characterization of Sensor Elements}

The morphology of the oxidized MWCNT, iron oxide nanoparticles, and the nanocomposites of oxidized MWCNT/iron oxide were investigated using a FESEM Hitachi S-4800 SEM. As shown in Figure 3, it can be seen that the MWCNTs form bundles due to the strong Van der Waals force. MWCNT diameters ranged from 4-10 nm. The image of the iron oxide presents clusters of the iron oxide nanoparticles that cling together and form aggregates in spherical shapes with individual sizes ranging from 5 to $50 \mathrm{~nm}$. The clusters of the iron oxide result from the magneto static coupling between 
particles [15]. The SEM images of the oxidized MWCNT/iron oxide nanocomposites show networks of MWCNT interwoven among the iron oxide nanoparticles. A research group has reported that the composite material is not just a mechanical mixture of the components, but they have detected chemical bonds, using infrared spectroscopy, between the carbon nanotubes and inorganic covering materials [16]. The iron oxide particles adhere to the surface of oxidized MWCNTs and also form small agglomerations as free particles. Overall, the iron oxide nanoparticles seem to be distributed uniformly on the surface of the MWCNT.

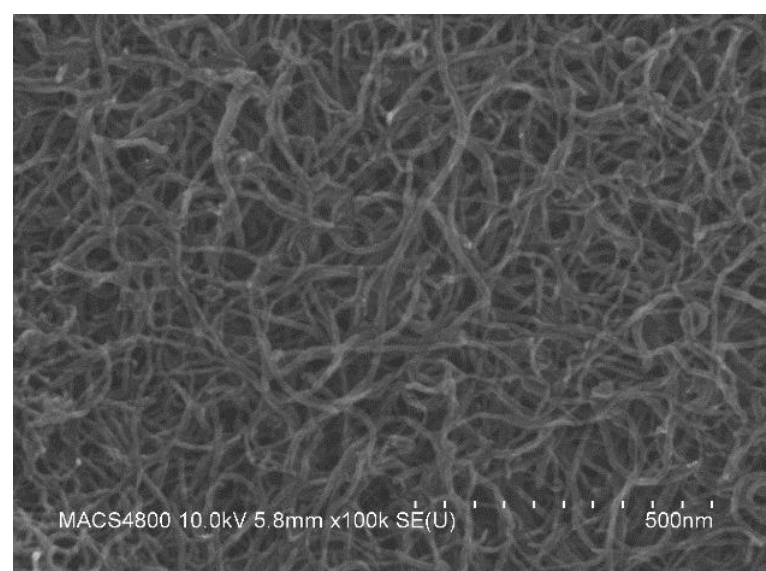

(A)

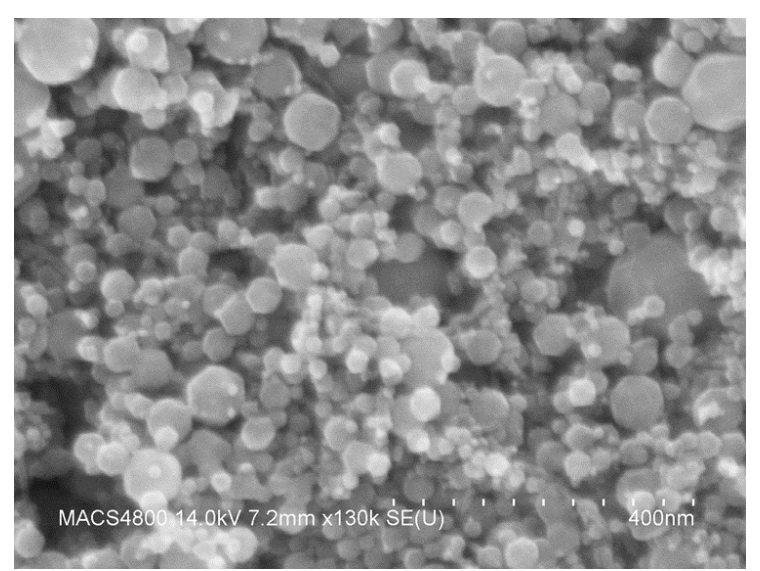

(B)

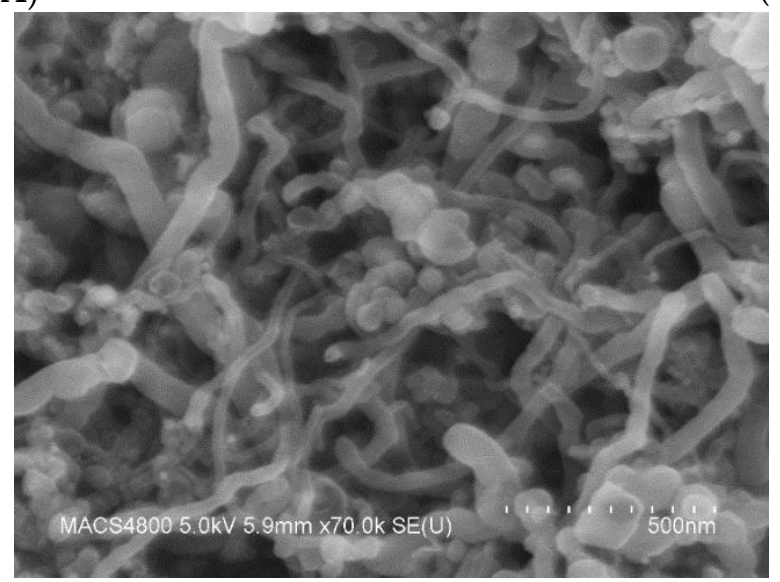

(C)

Figure 3. FE-SEM images for (A) oxidized MWCNTs deposited onto a silicon substrate, (B) iron oxide nanoparticles and (C) oxidized MWCNT/iron oxide composite material.

The bonding status of the oxidized MWCNT and MWCNT/iron oxide composite was checked using the wavelength-dependent transmittance data obtained using an FTIR spectrometer (Thermo Scientific, Waltham, MA, USA). Figure 4 shows the FTIR spectra for the oxidized MWCNT and oxidized MWCNT/iron oxide composite, respectively. The bands at around $1620 \mathrm{~cm}^{-1}$ in the spectra of both materials are associated with the $\mathrm{C}=\mathrm{C}$ vibrations, which result from the inherent structure of the nanotubes [15]. The absorption peak corresponding to the stretching vibration of $\mathrm{OH}\left(\sim 3400 \mathrm{~cm}^{-1}\right)$ indicates that oxygenated groups were produced on the surface of MWCNT after the acid treatment. The peaks at $1400 \mathrm{~cm}^{-1}$ are attributed to the $\mathrm{C}-\mathrm{OH}$ stretching and $\mathrm{O}-\mathrm{H}$ bending vibrations. Compared to the oxidized MWCNT, this peak increased in the spectrum of oxidized-MWCNT/iron oxide. As reported by other researchers, $\mathrm{C}=\mathrm{O}$ vibration of the carboxyl $(\mathrm{COOH})$ group was observed at $1735 \mathrm{~cm}^{-1}$ for oxidized MWCNT, and it disappeared from the MWCNT/iron oxide composite spectra. This could be the result of interactions between the negative charge from the carboxyl groups and positive charge from the iron oxide nanoparticles $[17,18]$. In the spectra of the oxidized MWCNT/iron oxide, the clear 
broadband around $580 \mathrm{~cm}^{-1}$ is due to the interaction of Fe-O-Fe and shows the presence of gamma iron oxide [17-19].

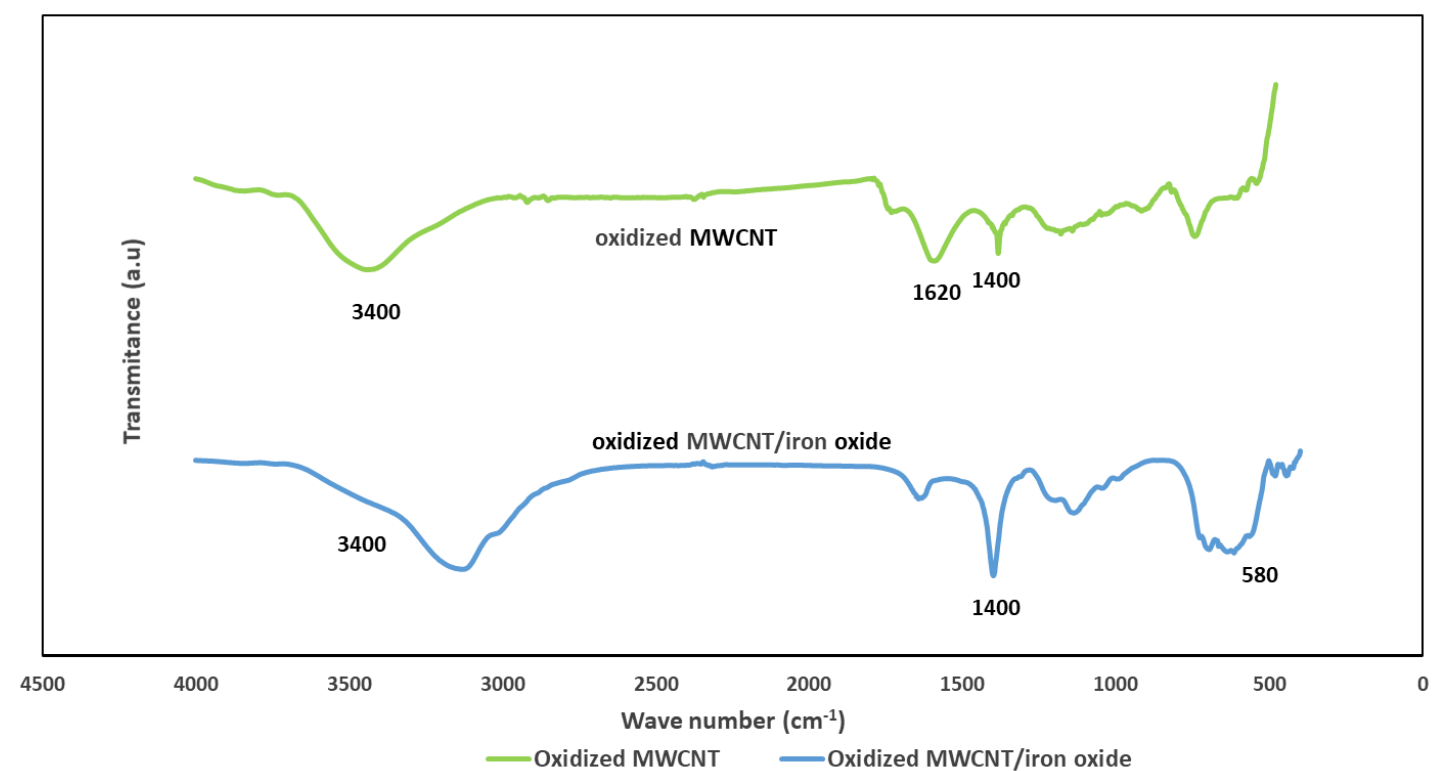

Figure 4. FTIR spectrum of the oxidized MWCNT and the oxidized MWNT/iron oxide composite.

Figure 5 shows the Raman spectra of both the oxidized MWCNT and the MWCNT/iron oxide composite. The Raman spectra were recorded at room temperature by a Renishaw Raman spectrometer with a linear laser excitation of $785 \mathrm{~nm}$ (He-Ne). For each sample, exposed for $10 \mathrm{~s}$, three distinct points were measured and displacement occurred between 100 and $1400 \mathrm{~cm}^{-1}$. It is well known that the sharp band at $1590 \mathrm{~cm}^{-1}$ ( $\mathrm{G}$ band) is attributed to the in-plane vibration of the $\mathrm{C}-\mathrm{C}$ bond, while the band at $1350 \mathrm{~cm}^{-1}$ (D band) is attributed to activation by the presence of disorder in the carbon systems $[19,20]$. The second-order peak at $2750 \mathrm{~cm}^{-1}$ is called 2D band. The Raman spectrum of oxidized MWNT/iron oxide showed a strong band at $671 \mathrm{~cm}^{-1}, 489 \mathrm{~cm}^{-1}$ and $280 \mathrm{~cm}^{-1}$, which are characteristic peaks of iron oxide nanoparticles [20,21]. It was also observed that the ratio of the the intensities of $\mathrm{D}$ band and G band (ID/IG) of oxidized MWCNT has been changed from 0.56 to 0.37 with the addition of iron oxide. The decrease in this ratio indicates that the atomic ordering of the MWCNT was enhanced and defects were reduced. This suggests that the iron oxide nanoparticles formed chemical bonds with the oxidized MWCNT surface [22].

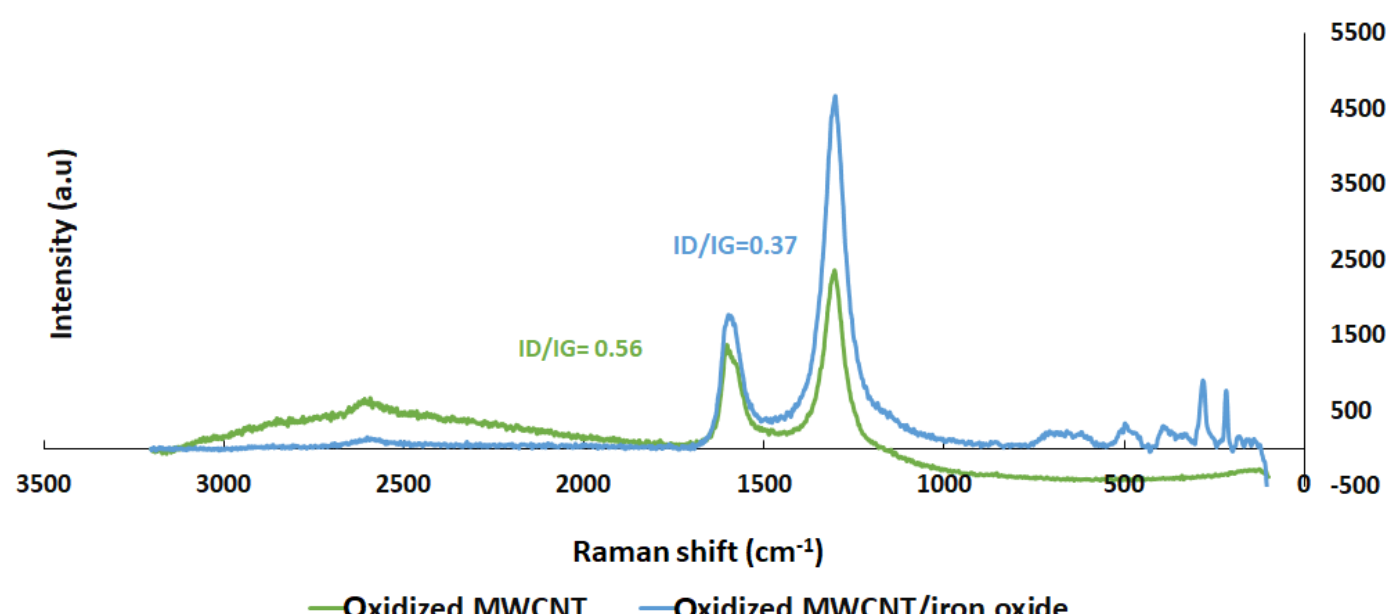

Figure 5. Raman spectra of oxidized MWCNTs and the oxidized MWNT/iron oxide composite. 


\subsection{Sensing Results}

The electrical resistance of the sensors at baseline and as sensor responses to $\mathrm{CO}_{2}$ were measured using the experimental set-up depicted in Figure 1. Oxidized MWCNT-based sensors have average base resistance around $1300 \Omega$, and the oxidized MWCNTs/iron oxide (3.5\% by weight) composite-based sensors have an average base resistance around 13,000 $\Omega$. The sensor chip was exposed, at room temperature, to $\mathrm{CO}_{2}$ concentrations of $100,200,400,800,1600,3800$ and $6000 \mathrm{ppm}$ at the interval stated in the Experimental section and as shown in the Figure 6. The response is normalized resistance $\left(R-R_{0} / R_{0}\right)$, where $R_{0}$ is the sensor base resistance with no $\mathrm{CO}_{2}$ exposure and $\mathrm{R}$ is the resistance at time $\mathrm{t}$ with $\mathrm{CO}_{2}$ exposure. We can see that the sensor resistance increased when it was exposed to various concentrations of $\mathrm{CO}_{2}$ gas, and this change was concentration dependent. Sensor response to the same sensing material channels is very similar (see Figure $6 \mathrm{~A}$ ) and the slight variations might be due to the manual deposition process. Figure $6 \mathrm{~B}$ shows the response curves from sensors made by two different sensing materials. From the response curves of the oxidized MWCNT sensor channels and the oxidized MWCNT/iron oxide channels, we observed that the response of the latter was improved greatly ( $\approx 5$ times). This may be due to the availability of the two possible locations for $\mathrm{CO}_{2}$ molecules adsorption, either at the MWCNT surface or at the iron oxide nanoparticles, which is a different sensing mechanism with the composite material $[23,24]$. As reported previously, hybrid metal oxide decorated carbon nanotubes showed an enhanced response as a gas sensing material due to a mechanism that induces a modulation of surface charges. Metal oxide has mainly n-type semiconductor characteristics and MWCNT have p-type semiconductor characteristics. These differences result in two depletion regions formed in such hybrid films. The first depletion region is located at the metal oxide surface and the second one is located at the interface between the metal oxide nanoparticle and the MWCNT. The adsorption of the $\mathrm{CO}_{2}$ molecule induces a modulation of surface charges that directly influences the electrons transfer between the heterojunctions and induces a variation in the resistance of the sensing layer [25]. Also, the presence of MWCNT in the iron oxide matrix can introduce nanochannels. These nanochannels play an important role in the gas diffusion process. The gas molecules can easily transport into the gas-sensing layers via these nanochannels, leading to increased sensitivity [26,27]. Similar results of enhanced responses have been reported with metal oxide and carbon nanotubes-based composite materials [23-29]. In addition, with the addition of iron oxide, the sensor response range seems to be increased. The oxidized MWNT-based sensor was saturated at $1600 \mathrm{ppm} \mathrm{CO}_{2}$, while the composite material-based sensor showed concentration dependence up to $6000 \mathrm{ppm} \mathrm{CO}_{2}$.

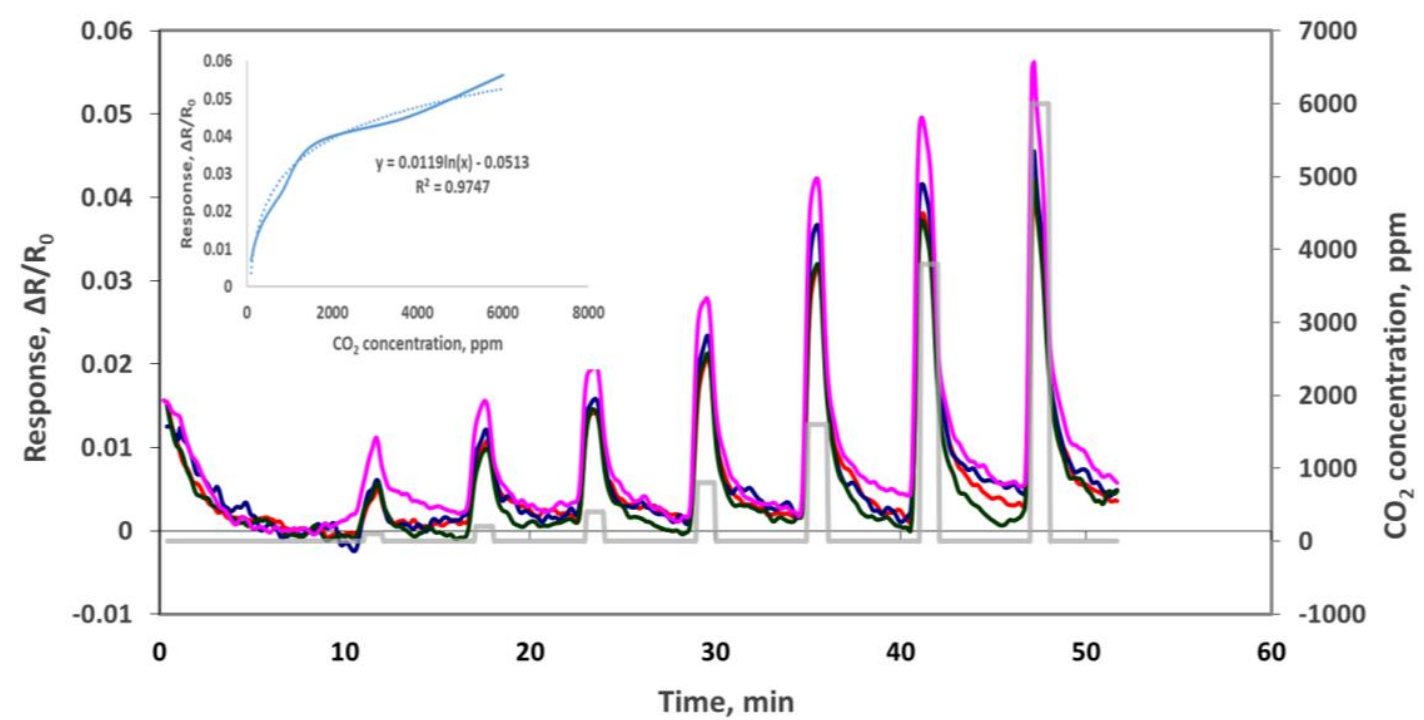

(A)

Figure 6. Cont. 

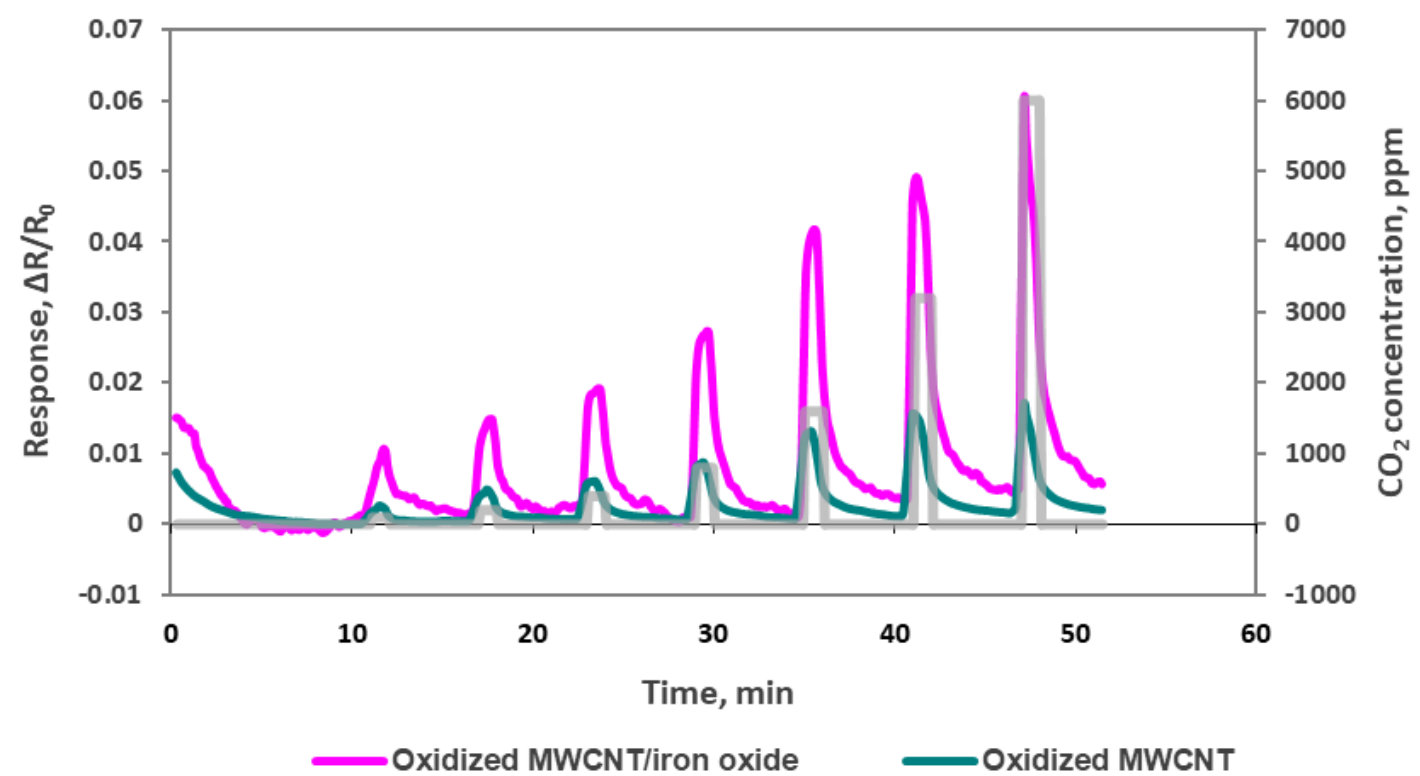

(B)

Figure 6. (A) Responses $\left(\Delta \mathrm{R} / \mathrm{R}_{\mathrm{o}}\right)$ to $100,200,400,800,1600,3800$ and $6000 \mathrm{ppm} \mathrm{CO}_{2}$ with oxidized MWCNT/iron oxide nanocomposite sensors. (B) Comparison of oxidized MWCNT/iron oxide nanocomposite and oxidized MWCNT response to 100, 200, 400, 800, 1600, 3800 and 6000 ppm $\mathrm{CO}_{2}$.

We also confirmed our chemiresistve sensor reponse with a commercial benchtop instrument-Sable System's CA-10 analyzer. This comparison assured the input $\mathrm{CO}_{2}$ concentrations of the sensor testing and also confirmed our sensor performance. We used a T-joint at the outlet of the Environics gas mixing system and allowed one stream to flow to the chemirestive sensor and another stream to $\mathrm{CA}-10 \mathrm{CO}_{2}$ analyzer. We can see in Figure 7 that the chemiresistive sensor response and recovery cycles match well with the CA-10 analyzer response pattern to $\mathrm{CO}_{2}$. In Figure 7, the blue line of the response curve was obtained from the $\mathrm{CA}-10 \mathrm{CO}_{2}$ analyzer in which the peaks corresponding to the $\mathrm{CO}_{2}$ concentrations are shown on the left $\mathrm{Y}$-axis, and the orange line of the response curve was obtained from our MWCNT/iron oxide sensor with a relative resistance change (right Y-axis) to the exposure of different $\mathrm{CO}_{2}$ concentrations. Our chemiresistive sensor takes about $10 \mathrm{~s}$ to reach a plateau that is comparable with the CA- $10 \mathrm{CO}_{2}$ analyzer. The accuracy of the concentration measurements of our sensor is also comparable with the commercial instrument. The response of our chemiresistive sensor to lower $\mathrm{CO}_{2}$ concentrations is more sensitive compared to the commercial $\mathrm{CO}_{2}$ analyzer. 


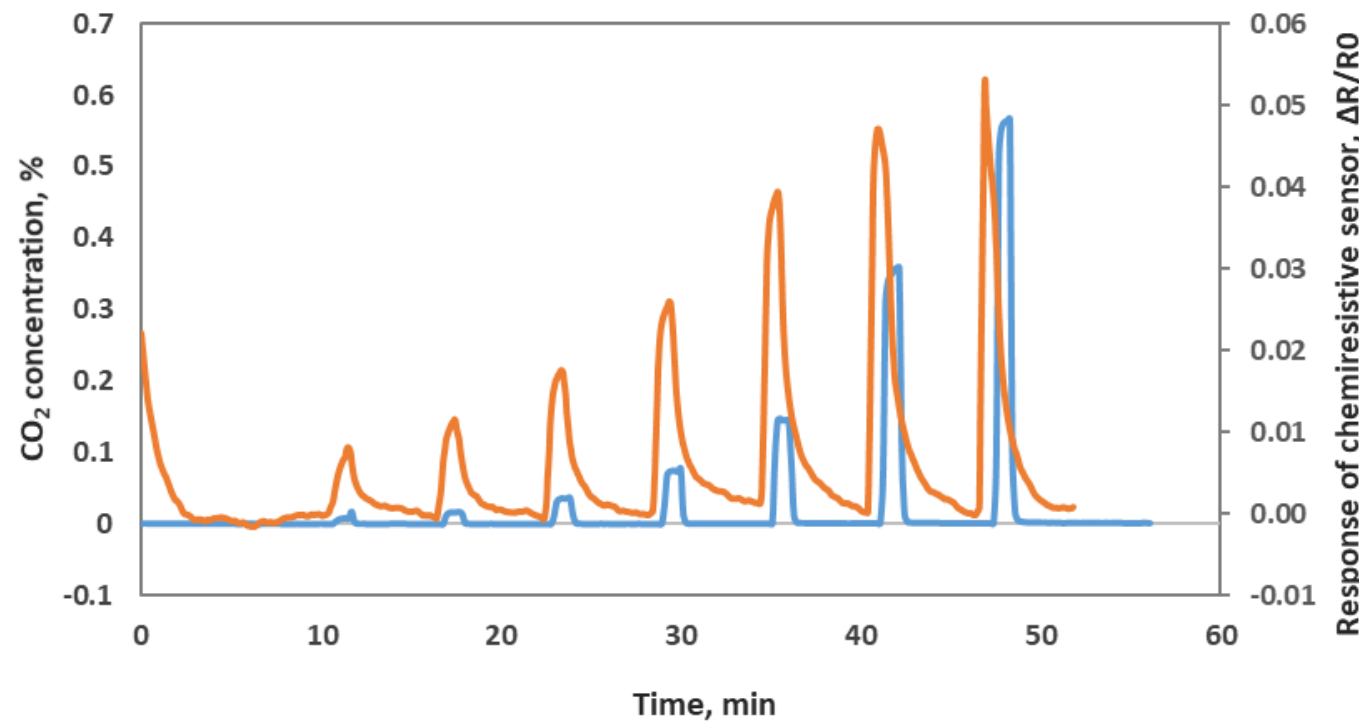

CA-10 MWCNT/iron oxide

Figure 7. Oxidized MWCNT/iron oxide chemiresistive sensor response along with $\mathrm{CA}-10 \mathrm{CO}_{2}$ analyzer response.

We also checked sensor performance for the case of increasing the $\mathrm{CO}_{2}$ concentration continuously step by step without air purge in between, as seen in Figure 8. Sensors were exposed to 100, 200, 400, 1000, 2000 and $4000 \mathrm{ppm}$ concentrations each for $1 \mathrm{~min}$ at room temperature. The sensor response time was very fast at about 5-10 s. All 4 sensor channels showed very similar responses to each other, which means these sensors are reproducible. In another experiment we checked the sensor's repeatability by exposing the sensor chip multiple times to $4000 \mathrm{ppm}$ of $\mathrm{CO}_{2}$. As we can see in Figure 9, the sensor chip showed a good response to $4000 \mathrm{ppm} \mathrm{CO}_{2}$, but the sensor response to the first $\mathrm{CO}_{2}$ exposure was higher than the rest of the $\mathrm{CO}_{2}$ exposures. This is normal chemiresitive sensor behavior and it shows that the sensor needs a warm up time to achieve a stable performance.

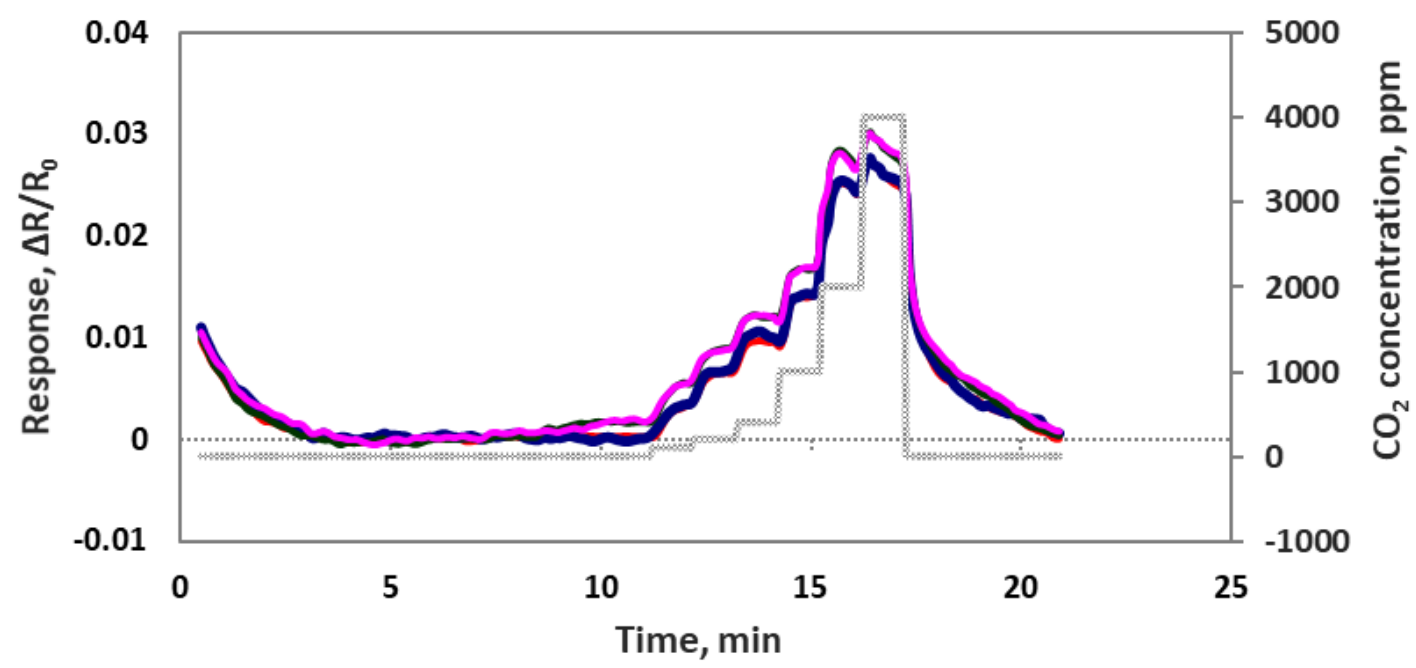

Figure 8. Four individual oxidized MWCNT/iron oxide composite sensor responses $\left(\Delta R / R_{o}\right)$ to the step input of 100, 200, 400,1000, 2000 and 4000 ppm $\mathrm{CO}_{2}$. 


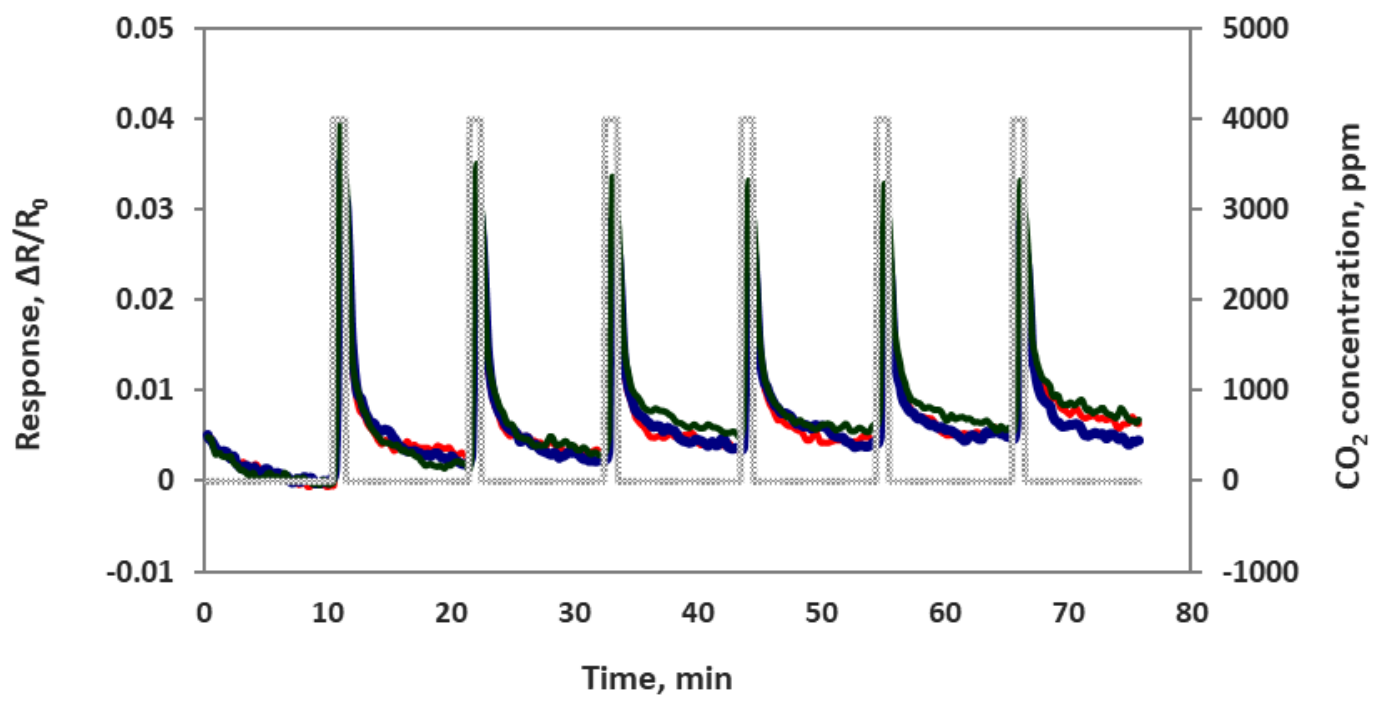

Figure 9. Composite material-based sensor responses $\left(\Delta \mathrm{R} / \mathrm{R}_{\mathrm{o}}\right)$ to muiltiple exposure of $4000 \mathrm{ppm} \mathrm{CO}_{2}$.

\section{4. $\mathrm{CO}_{2}$ Sensor Selectivity and Humidity Dependence}

To evaluate the selectivity of the MWCNT/iron oxide, the sensor chip was tested against 5 ppm acetone, $0.01 \mathrm{ppm}$ nitric oxide, $1 \mathrm{ppm}$ ammonia, $1 \mathrm{ppm}$ carbon monoxide, 10,000 ppm oxygen, and $1 \mathrm{ppm}$ sulfur dioxide in dry air at room temperature. These concetrations were chosen based on the most common concetrations of these species found in ambient air. Sensor response to $400 \mathrm{ppm}$ $\mathrm{CO}_{2}$ (presented in ambient air) was used to compare its response to these possible interferences, as seen in Figure 10A. The sensor showed some responses to few gases. However, these responses are negligible compared to the $400 \mathrm{ppm} \mathrm{CO}_{2}$ response. This indicates negligible cross sensitivity and adequate selectivity.

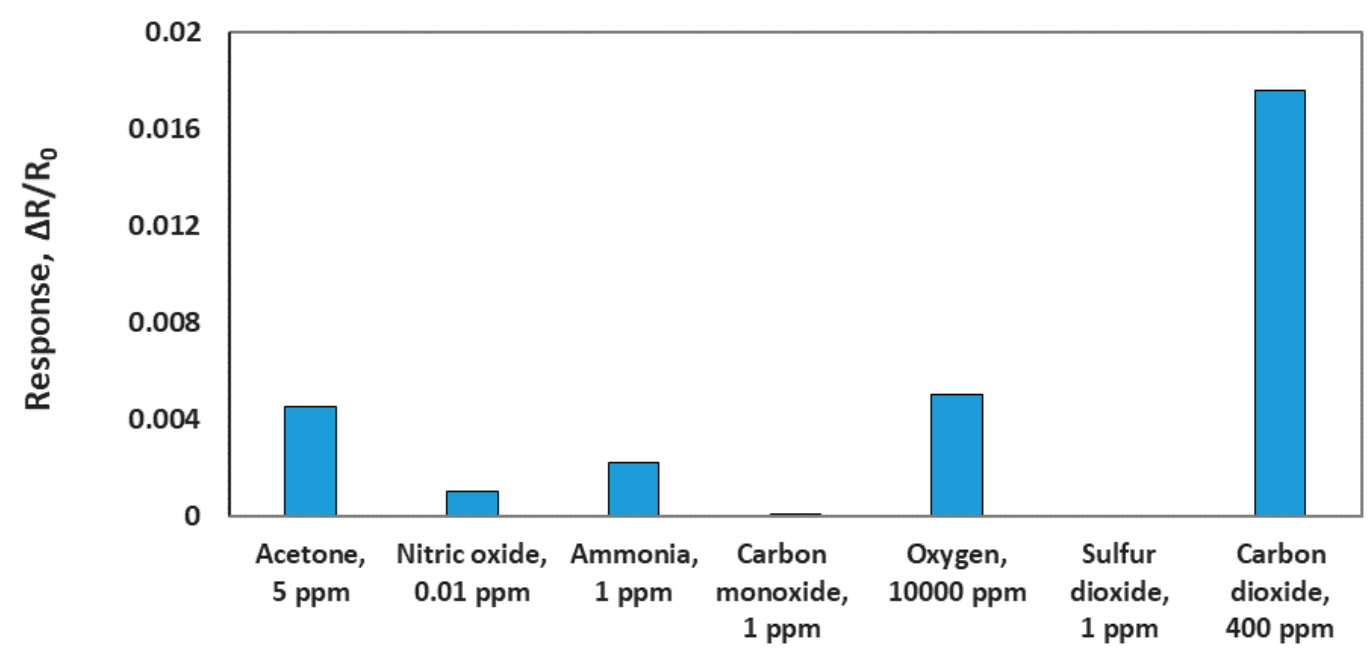

(A)

Figure 10. Cont. 


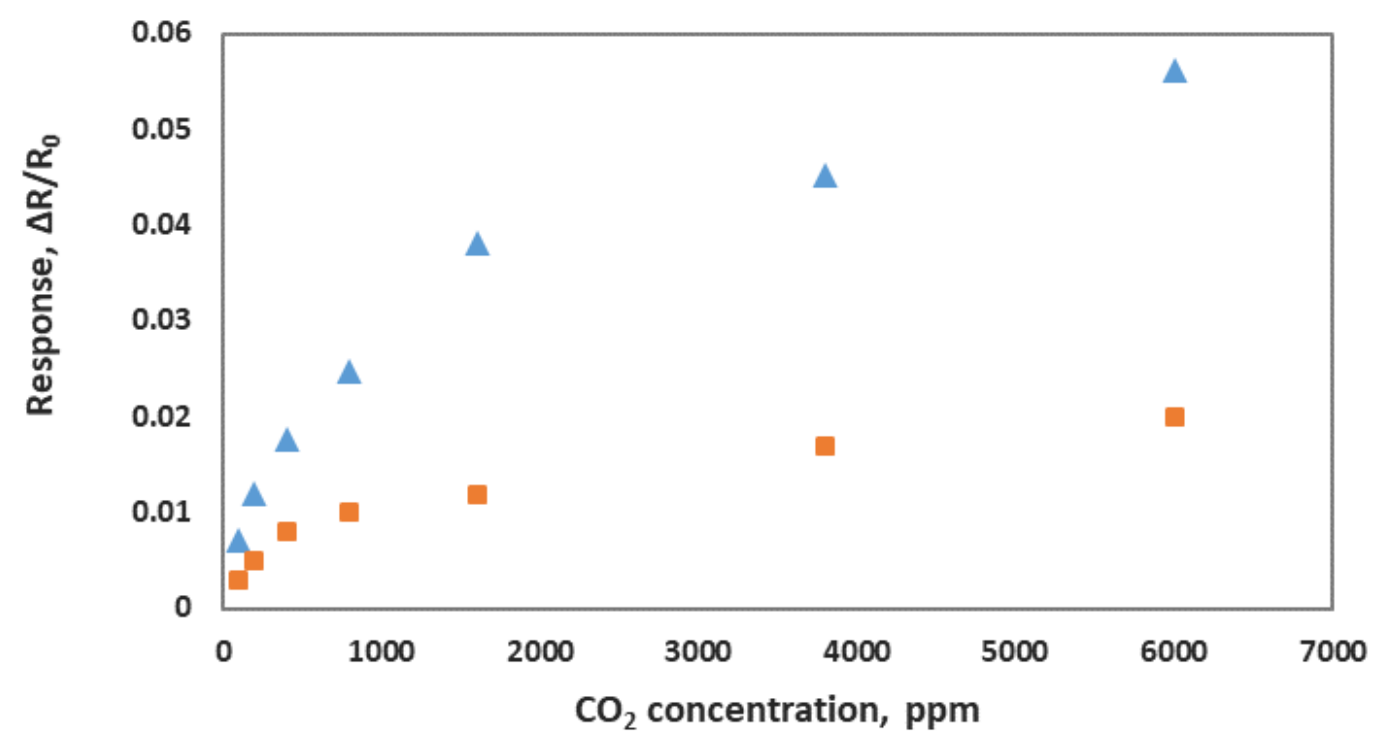

$\triangle 0 \% \mathrm{RH} \quad \square 25 \% \mathrm{RH}$

(B)

Figure 10. (A) Comparison of the sensor responses of $\mathrm{CO}_{2}$ and other gases. (B) Sensor response to various concentrations of $\mathrm{CO}_{2}$ at two different relative humidities $(\mathrm{RH})$.

Humidity's effect on the sensor response was investgated at room temerature $\left(25^{\circ} \mathrm{C}\right)$ with various levels of relative humidity (RH). The sensor chip was exposed to different concentrations of $\mathrm{CO}_{2}$ at a fixed value of humidity. As shown in Figure 10B, sensing response varied with the humidity and was significantly reduced at $25 \% \mathrm{RH}$. Sensors showed almost no response at $50 \% \mathrm{RH}$. This could be the result of water molecules blocking the $\mathrm{CO}_{2}$ adsoption on the surface of the sensing material. The dependence of sensor response on humidity seems to be a problem, but it can be addressed by using hydrophobic nanotubes or other techniques such as membrane filtration, dessicant drying and freezing seperation to remove the humidity effect.

\section{5. $\mathrm{CO}_{2}$ Sensor Intergration with A Smartphone}

As we reported in our previous publications [30,31], we have developed a sensor module that can be integrated with a smartphone, and it can sniff out trace amounts of gases in real time. Smartphone sensors have many advantages, such as low cost, compactness, low power consumption, easy operation, and network sensing capability. We deposited the composite sensing material of oxidized MWCNT/iron oxide onto a smartphone sensor chip that can be plugged into the sensor module. This sensor module was than plugged into a smartphone with an application that we developed for sensor data acquisition, storage and processing. The smartphone sensor was exposed to $\mathrm{CO}_{2}$ concentrations in the range of $100-8000 \mathrm{ppm}$, and the sensor responses were obtained, as shown in the Figure 11. The $\mathrm{CO}_{2}$ gas exposure was $2 \mathrm{~min}$ each, and the air purge was $10 \mathrm{~min}$ in the beginning and $5 \mathrm{~min}$ between $\mathrm{CO}_{2}$ exposures. The smartphone sensor showed a very good response to $\mathrm{CO}_{2}$ with quick response and recovery time in seconds. The corresponding calibration curves are shown in the inset. Using the same sensing material of MWCNT/iron oxide, a sensor chip measured to detect $\mathrm{CO}_{2}$ with a Keithley instrument and with the smartphone platform confirms that our chemiresistive sensor indeed works for $\mathrm{CO}_{2}$ detection. 


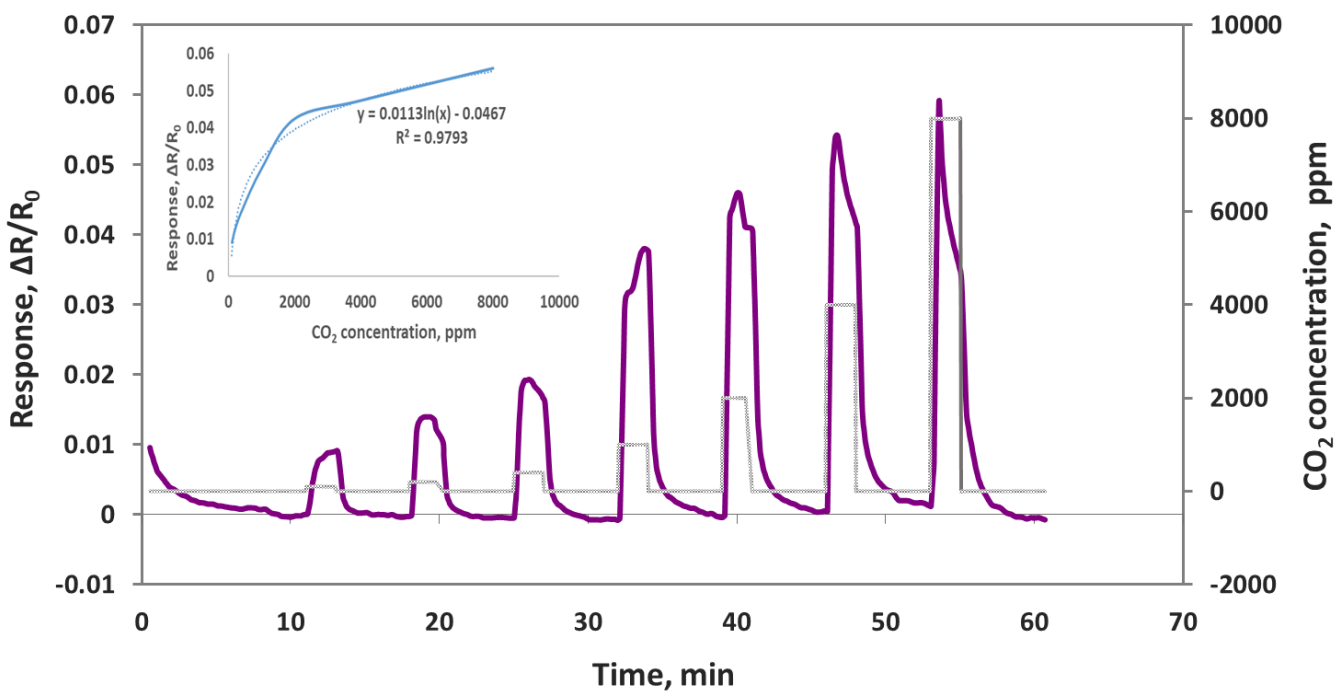

Figure 11. Oxidized MWNT/iron oxide composite sensor responses $\left(\Delta R / R_{o}\right)$ to $100,200,400,1000,2000$, 4000 and 8000 ppm $\mathrm{CO}_{2}$ on a smartphone device.

\section{Conclusions}

In this study, a chemiresistive sensor comprising of oxidized MWCNT and nanoparticles of iron oxide has been prepared and used as a sensing material for $\mathrm{CO}_{2}$ detection at room temperature. It was found that adding a small amount of iron oxide nanoparticles to MWCNT, we can enhance the sensitivity to $\mathrm{CO}_{2}$ by $\sim 5$ times, expand the detection range of the $\mathrm{CO}_{2}$ concentration from $100 \mathrm{ppm}$ to $6000 \mathrm{ppm}$, have quick response and recovery in $10 \mathrm{~s}$, and have good repeatability from measurement to measurement and good reproducibility from sensor to sensor. As reported by many researchers, this enhanced sensitivity is a result of nano-heterojunction formation at the interface between nanotubes and iron oxide nanoparticles. The presence of nano-heterojunctions induces a modulation of surface charges. In addition to the presence of carbon, nano-channels in the metal oxide enhance gas adsorption. These two mechanisms increase the sensor sensitivity manifold. We also calibrated the sensor chip with a commercial $\mathrm{CO}_{2}$ analyzer and our chemiresistive sensor showed comparable detection capability with advantages of smaller size, lower power, low cost and the ability to be easily multiplexed and integrated with existing electronics. We have also demonstrated $\mathrm{CO}_{2}$ detection using a smartphone sensing device that can be used for wireless and network sensing.

Our future work will focus on developing a methodology to pre-treat the sensor in order to shorten the warm up time. Based on the results of the humidity study, we need to remove the moisture from $\mathrm{CO}_{2}$ in the air stream.

Author Contributions: A.H. and J.L. conceived and designed the experiments; J.L. provide the methodology for conducting the experiment and data analysis; A.H. performed the experiments; A.H. and J.L. analyzed the data; A.H. and J.L. wrote the paper; J.L. provided the resources and acquired funding for this research.

Funding: This work was funded by NASA STMD Center Innovation Fund from NASA Ames Research Center. The work conducted by the employees of KBRwyle Incorporated and was supported through a contract number NAS2-03144 operated by the KBRWyle Inc.

Acknowledgments: Authors would like to thank Bin Chen for providing the Raman Spectroscope for conducing the Raman study on the carbon nanotube materials; Tra-My Justine Richardson for providing the benchtop $\mathrm{CO}_{2}$ analyzer for the sensor comparison study; and Yaroslav Popkov as a summer intern to help running the initial experiments.

Conflicts of Interest: The authors declare no conflict of interest. 


\section{References}

1. Permentier, K.; Vercammen, S.; Soetaert, S.; Schellemans, C. Carbon dioxide poisoning: A literature review of an often forgotten cause of intoxication in the emergency department. Int. J. Emerg. Med. 2017, 10, 10-14. [CrossRef] [PubMed]

2. Environmental Protection Agency (EPA). Carbon Dioxide as a Fire Suppressant: Examining the Risks, Report EPA430-R-00-002. Available online: https://www.epa.gov (accessed on 4 September 2018).

3. Occupational Safety and Health Administration (OSHA). Permissible Exposures Limits. Available online: https://www.osha.gov/dsg/annotated-pels/tablez-1.html (accessed on 11 November 2018).

4. Delgado-Alonso, J.; Phillips, S.; Berry, D.; DiCarmine, P.; Chullen, C.; Quinn, G. Continued Development of Compact Multi-gas Monitor for Life Support Systems Control in Space. In Proceedings of the 46th International Conference on Environmental Systems, Vienna, Austria, 10-14 July 2016.

5. Wang, Y.; Nakayama, M.; Yagi, M.; Nishikawa, M.; Fukunaga, M.; Watanabe, K. The NDIR $\mathrm{CO}_{2}$ monitor with smart interface for global networking. IEEE Trans. Instrum. Meas. 2005, 54, 1634-1639. [CrossRef]

6. Naama, S.; Hardjersi, T.; Keffous, A.; Nezzal, G. $\mathrm{CO}_{2}$ gas sensor based on silicon nanowires modified with metal nanoparticles. Mater. Sci. Semicond. Process. 2015, 38, 367-372. [CrossRef]

7. Michel, C.; Martinez-Preciado, A.; Parra, R.; Aldao, C.; Ponce, M. Novel $\mathrm{CO}_{2}$ and $\mathrm{CO}$ gas sensor based on nanostructured $\mathrm{Sm}_{2} \mathrm{O}_{3}$ hollow microspheres. Sens. Actuators Chem. 2014, 202, 1220-1228. [CrossRef]

8. Srinives, S.; Sarkar, T.; Hernandez, R.; Mulchandani, A. A miniature chemiresistor for carbon dioxide. Anal. Chim. Acta 2015, 874, 54-58. [CrossRef]

9. Wang, C.; Yin, L.; Zhang, L.; Xiang, D.; Gao, R. Metal Oxide Gas Sensors: Sensitivity and Influencing Factors. Sensors 2010, 10, 2088-2106. [CrossRef] [PubMed]

10. Wang, Y.; Yeow, J.T.W. A Review of Carbon Nanotubes-Based Gas Sensors. J. Sens. 2009, 2009, 1-24. [CrossRef]

11. Tang, R.; Shi, Y.; Hou, Z.; Wei, L. Carbon Nanotube-Based Chemiresistive Sensors. Sensors 2017, 17, 882. [CrossRef]

12. Zhang, Y.; Xu, M.; Bunes, B.R.; Wu, N.; Gross, D.E.; Moore, J.S.; Zang, L. Oligomer-Coated Carbon Nanotube Chemiresistive Sensors for Selective Detection of Nitroaromatic Explosives. ACS Appl. Mater. Interfaces 2015, 7, 7471-7475. [CrossRef]

13. Penza, M.; Rossi, R.; Alvisi, M.; Cassano, G.; Signore, M.A.; Serra, E.; Giorgi, R. Pt-and Pd-nanoclusters functionalized carbon nanotubes networked films for sub-ppm gas sensors. Sens. Actuators B Chem. 2008, 135, 289-297. [CrossRef]

14. Marliere, C.; Poncharal, P.; Vaccarini, L.; Zahab, A. Effect of Gas Adsorption on the electrical properties of single walled carbon nanotubes, mats. Mater. Res. Soc. Symp. Proc. 2000, 593, 173-178. [CrossRef]

15. Rahmawati, R.; Melati, A.; Taufiq, A.; Diantoro, M.; Yuliarto, B.; Suyatman, S.; Nugraha, N.; Kurniadi, D. Preparation of MWCNT-Fe ${ }_{3} \mathrm{O}_{4}$ Nanocomposites from Iron Sand Using Sonochemical Route. In IOP Conference Series: Materials Science and Engineering; IOP Publishing: Bristol, UK, 2017; Volume 202.

16. Aroutiounian, V.M.; Arakelyan, V.M.; Shahnazaryan, G.E.; Aleksanyan, M.S.; Hernadi, K.; Nemeth, Z.; Berki, P.; Papa, Z.; Toth, Z.; Forro, L. Ethanol sensors made from $\alpha-\mathrm{Fe}_{2} \mathrm{O}_{3}$ decorated with multiwall carbon nanotubes. Adv. Nano Res. 2015, 3, 1-11. [CrossRef]

17. Mitroova, Z.; Tomasovicova, N.; Lancz, G.; Kovac, J.; Vavra, I.; Kopcansky, P. Preparation and characterization of carbon nanotubes functionalized by magnetite nanoparticles. In Proceedings of the Nanocon2010, Olomouc, Czech Republic, 12-14 October 2010.

18. Cunha, C.; Panseri, S.; Iannazzo, D.; Piperno, A.; Pistone, A.; Fazio, M.; Russo, A.; Marcacci, M.; Galvagno, S. Hybrid composites made of multiwalled carbon nanotubes functionalized with $\mathrm{Fe}_{3} \mathrm{O}_{4}$ nanoparticles for tissue engineering applications. Nanotechnology 2012, 23, 465102. [CrossRef] [PubMed]

19. Panta, P.C.; Bergmann, C.P. Raman Spectroscopy of Iron Oxide of Nanoparticles $\left(\mathrm{Fe}_{3} \mathrm{O}_{4}\right)$. J. Mater. Sci. Eng. 2015, 5, 217. [CrossRef]

20. Wan, Y.; Shi, X.; Xia, H.; Xie, J. Synthesis and characterization of carbon-coated $\mathrm{Fe}_{3} \mathrm{O}_{4}$ nanoflakes as anode material for lithium-ion batteries. Mater. Res. Bull. 2013, 48, 4791-4796. [CrossRef]

21. Yang, L.; Hu, J.; Dong, A.; Yang, D. Novel $\mathrm{Fe}_{3} \mathrm{O}_{4}-\mathrm{CNT}$ nanocomposite for Li-ion batteries with enhanced electrochemical performance. Electrochim. Acta 2014, 144, 235-242. [CrossRef] 
22. He, Y.; Huang, L.; Cai, J.; Zheng, X.; Sun, S. Structure and electrochemical performance of nanostructured $\mathrm{Fe}_{3} \mathrm{O}_{4}$ /carbon nanotube composites as anodes for lithium ion batteries. Electrochim. Acta 2010, 55, 1140-1144. [CrossRef]

23. Hua, C.; Shang, Y.; Wang, Y.; Xu, J.; Zhang, Y.; Li, X.; Cao, A. A flexible gas sensor based on single-walled carbon nanotube- $\mathrm{Fe}_{2} \mathrm{O}_{3}$ composite film. Appl. Surf. Sci. 2017, 405, 405-411. [CrossRef]

24. Gupta, V.K.; Saleh, T.A. Synthesis of Carbon Nanotube-Metal Oxides Composites; Adsorption and Photo-degradation. In Carbon Nanotubes-From Research to Applications, 1st ed.; Bianco, S.B., Ed.; EdsIntechOpen: London, UK, 2011; Volume 17, pp. 295-312.

25. Ghaddab, B.; Berger, F.; Sanchez, J.B.; Mavon, C. Detection of $\mathrm{O}_{3}$ and $\mathrm{NH}_{3}$ using tin dioxide/carbon nanotubes based sensors: Influence of carbon nanotubes properties onto sensor's sensitivity. Procedia Eng. 2010, 5, 115-118. [CrossRef]

26. Wongchoosuk, C.; Wisitsoraat, A.; Tuantranont, A.; Kerdcharoen, T. Portable electronic nose based on carbon nanotube- $\mathrm{SnO}_{2}$ gas sensors and its application for detection of methanol contamination in whiskeys. Sens. Actuators B Chem. 2010, 147, 392-399. [CrossRef]

27. Wongchoosuk, C.; Wisitsoraat, A.; Phokharatkul, D.; Tuantranont, A.; Kerdcharoen, T. Multi-walled carbon nanotube-doped tungsten oxide thin films for hydrogen gas sensing. Sensors 2010, 10, 7705-7715. [CrossRef] [PubMed]

28. Zaporotskova, I.V.; Boroznina, N.P.; Parkhomenko, Y.N.; Kozhitov, L.V. Carbon nanotubes: Sensor properties. A review. Mod. Electron. Mater. 2016, 2, 95-105. [CrossRef]

29. Kerdcharoen, T.; Wongchoosuk, C. Carbon nanotube and metal oxide hybrid materials for gas sensing. In Semiconductor Gas Sensors, 1st ed.; Jaaniso, R., Tan, O.K., Eds.; Woodhead Publishing: Cambridge, UK, 2013; pp. 386-407. ISBN 9780857092366.

30. Li, J.; Hannon, A.; Lu, Y.; Kim, B.; Jesus, E.C.; Chen, J. A Phone-Sensor for Trace Chemical Detection. In Proceedings of the 43rd International Conference on Environmental Systems, Vail, CO, USA, 14-18 July 2013.

31. Hannon, A.; Lu, Y.; Li, J.; Meyyappan, M. A Sensor Array for the Detection and Discrimination of Methane and Other Environmental Pollutant Gases. Sensors 2016, 16, 1163. [CrossRef] [PubMed] 